\title{
Research Opportunities to Improve the Competitiveness by Using Network Project Teams
}

\author{
Sergey Novikov ${ }^{1}$, Natalia Komarova ${ }^{1} \&$ Karen $^{\text {Dadyan }}{ }^{1}$ \\ ${ }^{1}$ Moscow Aviation Institute (National Research University), Moscow, Russian Federation \\ Correspondence: Sergey Novikov, Moscow Aviation Institute (National Research University), Moscow, 4, \\ Volokolamskoe Highway, 125993, Russian Federation. E-mail: danonik92@mail.ru, ncsrm@mail.ru
}

Received: February 14, 2020

Accepted: March 10, 2020

Online Published: March 19, 2020

doi:10.5430/rwe.v11n1p212

URL: https://doi.org/10.5430/rwe.v11n1p212

\begin{abstract}
This article shows the relevance of the problem of increasing the competitiveness of Information Technology (IT) companies as part of the fourth industrial revolution and presents the relevance of the implementation of network project teams to improve the competitiveness of IT companies. The paper presents the hypothesis, purpose, object and subject of research and shows the practical significance and novelty of the work. There are possibilities of increasing the competitiveness of IT companies in the framework of the aerospace industry. The paper presents the industry's need for automated systems required for air transportation. We can find the correlation of the emergence of new management tasks with the presence of such components as new management standards, the growth of the number of holdings, financial and industrial groups and the total number of enterprises. It presents the advantages of using network project teams for solving complex and non-standard tasks within a limited time resource. Furthermore, it shows a comparison of the two approaches using the network and conventional project team. It is shown that the usual project team does not have the capabilities that will ensure the high competitiveness of the company in the implementation of complex, non-standard projects, where it is impossible to do without new knowledge and competencies and complete the project in a limited time. Also, it describes the process of transformation of an ordinary group into a network structure. Also, this article also illustrates possibility to avoid many negative characteristics of a conventional group while maintaining the basic principles of the project team and its positive characteristics.
\end{abstract}

Keywords: aerospace industry, competitiveness, fourth industrial revolution, information systems, IT companies, network project teams

\section{Introduction}

In previous studies it was found that within the fourth industrial revolution there is a large number of new information and communication technologies, and the demand for information systems is steadily increasing, as well as the competition in this industry.

The relevance and the problem of the study is determined by the fact that in modern economic conditions the IT industry is in great demand and is developing very quickly. Russia has a great potential of specialists who are involved in the process of creating information systems (Akhramovich, Borisova \& Odinokov, 2017). However, the number of tasks that are set in front of the IT industry is increasing and their complexity is increasing too.

In addition, there is often a need to implement complex, non-standard projects in the shortest possible time. At the same time, competition from Western companies is increasing and the information systems, hardware and software systems that use imported software are used in many industries. They can be used in aviation and marine navigation systems, in control systems for power plants, manufacturing enterprises and other complex facilities, including defense industry. (Ni, Wang, Che, Hong \& Sun, 2019). This increases the vulnerability of industries in terms of economy and state security.

In the same situation it is necessary to consider the speed of changes in foreign economic processes, given the pressure that comes from outside the imposed expansion of foreign information systems and competition within the industry and to provide an opportunity for rapid reaction of domestic companies with adequate measures. These measures will strengthen its position, minimize vulnerability, increase resource and successfully compete with 
leading Western companies in the IT industry.

One of these measures is to use the network (distributed) project teams. Such organization of project forms of activity has many advantages over the usual project team in terms of rapid response to changes in the external environment. Thus, the problem of the research is the necessity for the purposes of increasing the competitiveness of the IT company to transform the project team into a network one (Grosspietsch \& Silayeva, 2006).

The degree of scientific development of the problem is based on the results of previous studies of the authors presented in the textbook. The authors of the presented work showed the advantages of network management structures. The authors of the presented work showed the advantages of network management structures. During the 20th and 21st century in the academic literature it has been widely discussed the issue of the transformation of rigid corporate structures to more soft, decentralized ones. Other considered topics are the transformation of the traditional hierarchical pyramid and the emergence of the so-called "flexible" organizations (Arzeni \& Pellegrin, 1997; Tapscott, Lowy, Ticoll, \& Klym, 1998; Carney, 1998; Philip \& Jerome, 1998). At that time, the conception of a creative network appeared in the literature, involving interrelated, multidirectional and multi-level relationships within the value chain, which can lead to better innovations and their faster implementation.

Based on the analysis of these conceptions, in this paper it is proposed for the first time the term of network project teams. Previously, we have not seen in the literature the use of it in relation to project teams.

The results of scientific research of, for example, Jonathan Cummings, associate professor of management at Duke University School of Business in Durham, North Carolina and Carol Pletcher, the President of Pletcher Incorporated, the innovation consulting company in Saint Paul, Minnesota confirm that the most effective method of working in the implementation of the project approach is to create the project networks. The studies conducted by these authors show that the network project team combines the capabilities of a conventional project team and the opportunities of the personal connections of participants, which have a synergistic effect. This combination is the basis of an additional resource, which provides a competitive advantage (Cross \& Cummings, 2004; Cummings \& Cross, 2003; Merrone, 2010).

In this paper you can find the conception of network project teams, based on the analysis of them.

Let's deal with this approach. Two terms, project team and project team, are used in different sources. Therefore, before talking about the design forms of work, both conventional and network, it is advisable to define the terms that will appear in the future.

The project team is a temporary educational organization of people with a leader at the head, which usually has the mission of achieving one important goal (Tsvyk, V, \& Tsvyk, I., 2017). It includes a set of all the necessary specialists to perform the task as scheduled.

A project team is a group of people who perform project work, it has a structure and a manager. That is almost the same as the project team, but we use it less often (Callari, Bieder \& Kirwan, 2019).

After many years of application and adjustment of the processes of formation and management of project teams, well-established mechanisms were obtained, which allowed to achieve good results. But all this work was mainly carried out in Western companies. So, two words appeared later: "team" and "group".

The conception and classification of "team" was used by Japanese managers working in Western countries.

In network project team each of the participants can be involved in remote work, providing that they have the competencies that are necessary to solve the problems of the project. Both independent consultants and employees of other companies can be invited. Thus, the project network combines the capabilities of an ordinary project team and the opportunities found through the personal connections of its members.

A typical project team is formed from among the company's employees or with the participation of specialists involved. But the process of creating a group and achieving the starting state is complicated by the need for a physical presence on the territory of the developer company. As a result, the process of attracting specialists is becoming more complicated. The reasons are an increase in the number of critical obstacles, such as a significant distance from the place of work, proposed schedule, etc. that are limitations for potential employees, but at the same time not related to the level of competence of them.

In a network team, an employee can be physically located at any distance. Only a reliable communication mechanism is needed. This reduces the time to find and hire highly qualified specialists, regardless of the barriers of territorial remoteness or bureaucratic procedures. You can connect specialists in different time zones on a specific production schedule, which allows to organize round-the-clock work on the project. It is possible to employ unique 
specialists of different spheres after changing one task to another. The employees have the opportunity to hire and to engage other people, if they have a lack of necessary competence.

Based on the above, we can hypothesize that the use of network (distributed) project teams will allow companies to carry out complex, non-standard projects, which will ensure the competitiveness of the company in the face of growing competition and strengthening the dynamics of the economic environment.

Thus, by expanding the space for finding the necessary measures to improve the competitiveness of companies using the project approach in their activities and guided by the principle of increasing the ideality of the system, the following hypothesis can be put forward. Competitive advantages will be provided by a group formed from the number of employees with the best competencies to perform a specific task, composed in the shortest possible time and as a result, able to offer the best solution in a short period of time. This result can be achieved by appropriate selection and involvement of employees for remote work, so the group becomes distributed or network.

This approach will reduce the isolation of employees, will increase information and technical resources, will expand the space for the selection of the most suitable specialist (regardless of its location), will eliminate the fragmentation of resources (although it will complicate the access to them) and will accelerate the development of production and scientific and technical potential of the company (subject to the accumulation and systematization of information about the acquired resources). These changes will allow the company to gain competitive advantages by improving the quality of the proposed solutions and reducing the time of their implementation. Also, the company's opportunities to implement several projects at the same time will increase.

Based on the above, we can put forward the following hypothesis. Transformation of the project group into a network at the optimal stage of the project group life cycle allows to obtain competitive advantages of the company and increase its socio-economic efficiency. In turn, this will allow to implement difficult, complex, non-standard projects, which is extremely important in the context of growing competition.

The transformation criteria will be socio-economic efficiency indicators, the values of which are obtained before and after the transformation of the usual project group into a network (Gorodnikova, Gokhberg, Ditkovsky, 2018).

The aim of the study is to improve the competitiveness of IT companies through the use of network project teams when it is necessary to solve a new task or a non-standard one in conditions of increased competition and internal resource scarcity.

The object of the study is the dependence of the company's competitiveness on the use of network project technologies in the segment of the IT market in the aerospace industry (Xu, Chan \& Zhang, 2018).

The subject of the study is a set of properties possessed by conventional and network project teams and through which it is possible to increase the competitiveness of the company engaged in project activities.

The practical significance of the work has the conclusions that can be considered as the basis for the construction and operation of network project teams for IT companies.

The scientific novelty of the work is that there is the relationship between the use of network design approach and the competitiveness of the company in the implementation of complex and non-standard projects. The factors that complicate the work of the project group were found when the group face with the necessary of unusual or new solutions. It is planned to develop an approach to determine the feasibility of using network project teams.

The competitiveness of IT companies specialized in the development of information systems for the aerospace industry depends on whether they implement and maintain existing systems or develop new ones. The competitiveness of the latter ones is much higher. The domestic aviation industry is currently dominated by IT companies that perform mainly service functions and only a minor revision of the systems, which is limited by the terms of the license agreement. Most of the information systems in the industry were created by foreign companies, so in some technical issues the dependence of consumers is greater than if the development of systems were carried out by domestic companies. At the same time, there are issues in which dependence on foreign companies is simply unacceptable.

Thus, at the moment the need for the development of information systems and hardware and software systems for the aerospace industry tends to increase. Airlines need systems that provide storage and processing of information resources, which, in turn, are now rapidly increasing in volume. Therefore, systems that meet the requirements of the industry trends and ensure any kind of activity related to air transportation are needed (Glushak, 2011; Novikov, 2018; Ketabdari, Giustozzi, Crispino, 2018). 


\section{Methodology}

The tasks arising in the organization and implementation of air transportation need automated systems of the following types (Zelentsova \& Tikhonov, 2019):

- universal processing systems for payment of air tickets and non-aviation services;

- customer relationship management systems;

- e-Commerce systems for airlines;

- online booking systems (B2B);

- online booking statistics system;

- software and hardware systems for storing databases of electronic tickets;

- reservation analysis and control systems;

- $\quad$ system representing a complete solution for airlines;

- graphic terminal booking system;

- online check-in of passengers and baggage, system of self-registration of passengers.

Agencies that work with air content and sales of additional services use tools, including such systems as:

- online booking systems (B2B and B2C)

- $\quad$ automated distribution system (ARS)

- graphic terminals for reservation systems

- $\quad$ settlement system TKP (Transport clearing House)

- mutual settlement systems IATA BSP (International Air Transport Association Billing \& Settlement Plan) and others.

The emergence of new management tasks associated with the presence of such components as new management standards, financial reporting, analysis and business planning, project management, necessitates the creation of new tools (Truong, Friend \& Chen, 2018). The increase in the number of holdings, financial and industrial groups and the grow in the total number of enterprises in different industries causes the multiplication of the volume of information flows and the increase in the requirements for the level and degree of automation. This process increases requests for the tools that you create. In addition, in conditions of competition and low readiness to resist "pirated" products, there are more requirements for the quality of domestic developments.

Under these conditions, the companies of the software industry get more tasks and the number of their species increase. The IT industry is experiencing a shortage of developers, managers and IT project managers. It is important to consider that over the past few years, the practice of performing work by different development centers within the same project has been established. At the same time, the centers can be located both within the same organization and in different countries. But at the moment, companies have a low willingness to work in the conditions of redistribution of development centers (Komarova \& Kuznetsova, 2018).

The project team often carries out the development based on technical and production knowledge that has the team, guided by the goal and expecting only that the client will provide the necessary information. As a result, many opportunities to create a better solution and achieve a better economic result are missed. In addition, in most cases, the project teams have increased the risks associated with the limited prospect of further project activities. Some factors affect the functioning and capabilities of the project team. With the increasing number of non-standard, complex tasks in a limited time frame and increasing requirements for development, the capabilities of project teams are not enough. This reduces the competitiveness of companies. It is necessary to increase the capabilities of project teams, which, first of all, will improve the quality of the developed systems and increase the competitiveness of IT companies. The use of network project teams is proposed as a solution to these problems. A network project team is a team that consists of a core group of team members who engage additional participants (for example, employees of other companies located geographically far away or even in other countries, suppliers, consulting organizations or customers) from their personal networks and relationships that can provide the necessary knowledge, information or other assistance. Thus, the project network combines the advantages of the project team and the personal ties of its members.

The success of the interaction of software production centers largely determines the choice of the model of 
interaction of such centers, as well as models of management of network project teams. The correct organization of their interaction is extremely important for the successful interaction of remote units. Many countries today have a successful experience of such interaction, and one of them is Russia (Novikov \& Veas Iniesta, 2018). But there are factors that undermine the image of Russian companies-developers of information systems, which in the world market can complicate the interaction between development centers located in different countries.

Some tasks may be beyond the control and influence of the normal working group. Such situation is possible when the necessary human and financial resources are dispersed among different units or organizations and structural barriers, or when difficulties in securing and financing need to be overcome.

It is not always clear whether a group can perform a complex, multi-stage task assigned to it for the first time and requires new knowledge and skills, that is, whether the performance of this task is commensurate with the capabilities of the group or there is another optimal solution for the organization to perform this task. The knowledge necessary to solve any task that determines the success of the project is outside the organization. Also, the need for the development of domestic systems is increasing, as for some activities the use of information systems of foreign production is excluded. In strategic industries, the demand for information systems is one of the largest (Novikov, 2018).

Summarizing all the above, in order to increase opportunities, there is a need to transform ordinary project teams into such structural units that would have the resources and capabilities to work successfully in the conditions of redistribution of development centers. In this case, the acquisition of experience in the use of distributed or network project teams becomes particularly important.

The figure below shows the factors that affect companies, the requirements that companies put forward for information systems and the process of performing the tasks of developing new systems or upgrading old ones by the organization applying the project approach (Figure 1).

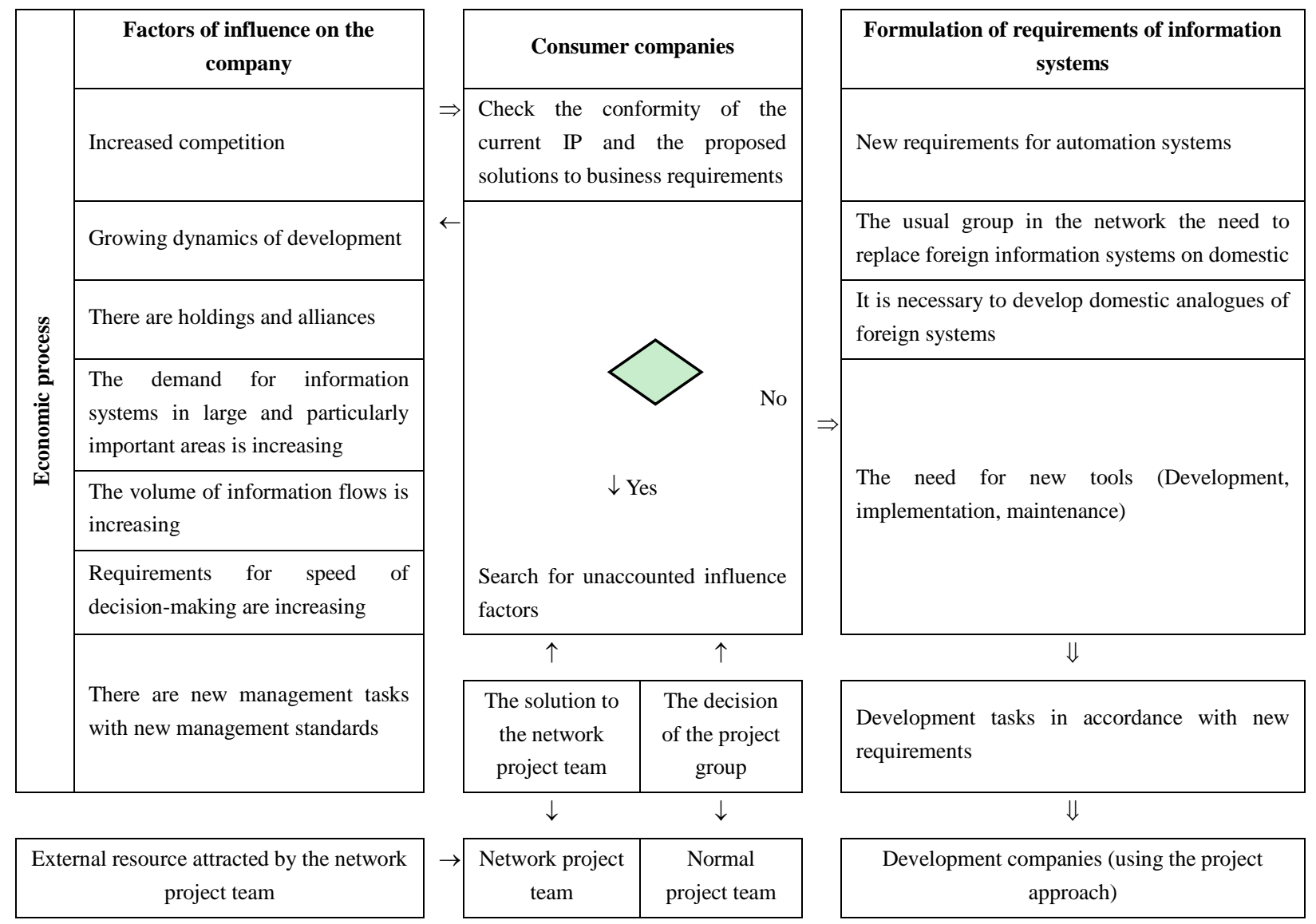

Figure 1. The principal difference between the two approaches when using the network and normal project team 
Thus, the problem is that the usual project team does not have the capabilities that will ensure high competitiveness of the company in the implementation of complex, non-standard projects, where it is impossible to do without new knowledge and competencies and complete the project in a limited time (Novikov, 2019).

There is a need to change the properties of the project team so that it will eliminate or reduce the shortcomings of the usual project team and also make it possible to perform complex, non-standard projects and reduce the time of their implementation (it will increase the possibilities) (Figure 2).

At the same time, it is necessary to maintain the project approach. Thus, an ordinary project team is transformed into a network one. At the same time, it is important to explore the mechanism that allows you to implement and control the necessary changes and guide them in the right direction.

In the process of transformation, it is necessary to get rid of a lot of negative characteristics while maintaining the basic principles inherent in the project team and maintaining its positive characteristics. In particular, the solution of such a task should allow: to get rid of isolation, to be able to connect to a new information field and opportunities, to reduce the time at the stage of team response, to improve and maintain the moral climate, to achieve a greater degree of formalization of data, to reduce the fragmentation of resources, and to eliminate duplication of functions while maintaining the existing the current positive aspects inherent in the usual project team.

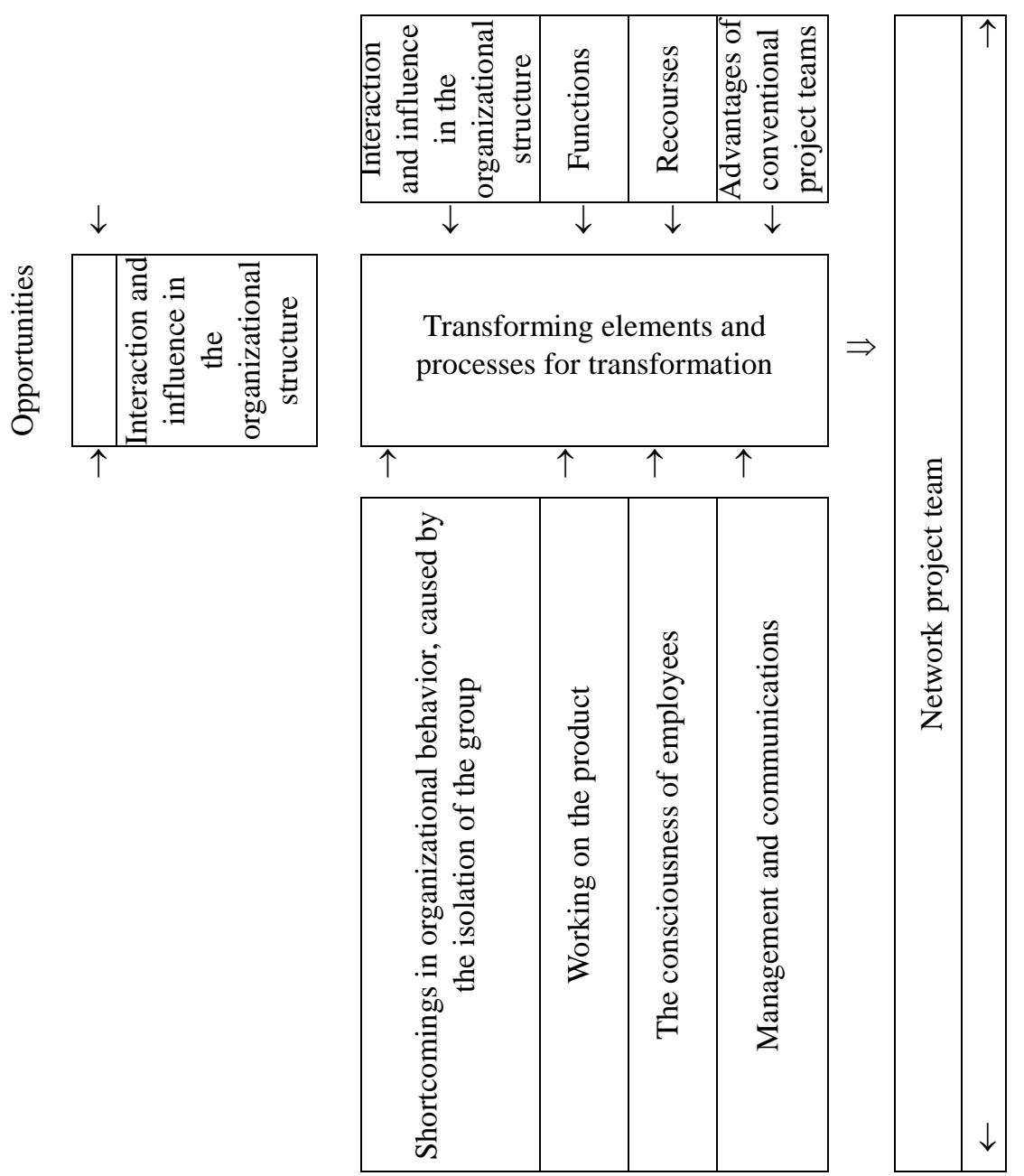

To plan studies, it is necessary to identify a complete list of factors, the change of which may increase or decrease the capabilities of the project team. The effect of such factors can be changed in the desired direction.

Figure 2. Transformation of an ordinary project team into a network one 


\section{Conclusions}

In the article we include the new term "network project team" and we construct the logical structure of the study. During the formation of the considered research problems, we have identified and considered various groups of factors that reduce the competitiveness of IT companies in solving problems in the development and implementation of various types of information systems for the aerospace industry. In the course of solving these problems, we have found the need to use a network approach to address the multi-functional and rapidly changing challenges faced by developers of information systems.

We have shown a fundamental difference between the approaches to solve the identified tasks of the project group and the network one, which consists of different resources and possibilities. On the basis of the obtained difference in approaches, we constructed a schematic diagram of the transformation of an ordinary project group into a network one. This transformation will solve the problem of increasing the competitive advantages of the company, will increase its socio-economic efficiency and will allow implementing complex and non-standard projects in conditions of resource deficit and severe time limits.

To ensure the above advantages of networked project structures, it is necessary to select a model of network organizational team corresponding to the project type. This choice is especially important at network interaction of the development centres, especially in cases when requirements to quality and speed are critical. For this purpose, a system of classification of project types and network team models is required. And also search for pairs consisting of a project and a team in which application of the selected team model will be most preferable for implementation of a particular project. For this purpose, it is necessary to develop parameters by which it is possible to estimate the optimal combination of the model and the project type. And also it is necessary to take into account the shortcomings of network and virtual organizational structures. Weaknesses in the network structures need to be strengthened or eliminated. It is necessary to develop a mechanism of authorization and commissioning of new employees, including the development of an employee passport, and a mechanism for forming the necessary model of network structure or transforming it from the existing one.

The development results represent a working tool for the implementation of specialized internal company management.

Implementation of the proposals and recommendations presented in the work will allow IT companies improving their financial and economic performance.

The research results can be used by managers and specialists of enterprises. They allow intensifying process of the organisation of manufacture of new production; estimating potential of industrial system and possibility of its change; operating processes of development of the organisation of manufacture taking into account a developed situation in the conditions of dynamically changing environment.

\section{References}

Akhramovich, A., Borisova, E., \& Odinokov, S. (2017). Lean Manufacturing in Russia: Myth or Reality?. International Conference on Quality, 410-414.

Arzeni, S., \& Pellegrin, J-P. (1997). Entrepreneurship and local development. Organisation for economic cooperation and development. The OECD Observer, 204, 27-29.

Callari, T. C., Bieder, C., \& Kirwan, B. (2019). What is it like for a middle manager to take safety into account? Practices and challenges. Safety Science, 113, 19-29.

Carney, M. (1998). The competitiveness of networked production: The role of trust and asset specificity. Journal of Management Studies, 35(4), 457-479.

Cross, R., \& Cummings, J. (2004). Tie and Network Correlates of Individual Performance in Knowledge-Intensive Work. Academy of Management Journal, 47(6), 928-937.

Cummings, J., \& Cross, R. (2003). Structural Properties of Work Groups and Their Consequences for Performance. Social Networks, 25(3), 197-210.

Glushak, O. V. (2011). Methodological aspects of research innovation. Creative Economy, 5(6), 44-48.

Gorodnikova, N. V., Gokhberg, L. M., \& Ditkovsky, K. A. (2018). Indicators of innovation: 2018. Statistical collection. Moscow: National Research University Higher School of Economics.

Grosspietsch, K. E., \& Silayeva, T. (2006). Organic computing - a new paradigm for achieving self-organized dependable behavior of complex IT systems. 14th Conference on Interdisciplinary Information Management 
Talks, 13-15.

Ketabdari, M., Giustozzi, F., \& Crispino, M. (2018). Sensitivity analysis of influencing factors in probabilistic risk assessment for airports. Safety Science, 107, 173-187.

Komarova, N. V., \& Kuznetsova, A. D. (2018). The study of problems and development strategy of the airline. Microeconomica, 3, 14-17.

Merrone, J. (2010). Team Boundary Spanning: A Multilevel Review of Past Research and Proposals for the Future. Journal of Management, 36(4), 911-940.

Ni, X., Wang, H., Che, C., Hong, J., \& Sun, Z. (2019). Civil aviation safety evaluation based on deep belief network and principal component analysis. Safety Science, 112, 90-95.

Novikov, S. V. (2018). Russian Support for Innovation and Export Growth. Russian Engineering Research, 38(4), 305-308.

Novikov, S. V. (2019). Problems of the Russian Economy Integration in the Sphere of High-tech Global Space. TEM Journal, 8(1), 207-210.

Novikov, S. V., \& Veas Iniesta, D. S. (2018). State regulation of the development of the connectivity of the Russian territory. Espacios, 39(45), 8.

Philip, P. A., \& Jerome, H. (1998). Transforming supply chains into value webs. Strategy and Leadership, 1, 6-11.

Tapscott, D., Lowy, A., Ticoll, D., \& Klym, N. (1998). Blueprint to the digital economy: Creating wealth in the era of e-business. New York: McGraw-Hill.

Truong, D., Friend, M. A., \& Chen, H. (2018). Applications of Business Analytics in Predicting Flight On-time Performance in a Complex and Dynamic System. Transportation Journal, 57(1), 24-52.

Tsvyk, V., \& Tsvyk, I. (2017). Philosophy of Technology in the System of Modern Education. 3rd International Conference on Economics, 25-26.

$\mathrm{Xu}$, S., Chan, H., \& Zhang, T. (2018). Forecasting the demand of the aviation industry using hybrid time series SARIMA-SVR approach. Transportation Research Part E-logistics and Transportation Review, 122, 169-180.

Zelentsova, L. S., \& Tikhonov, A. I. (2019). Differential-Integral Approach to the Competition Resistance Evaluation of Aircraft Engine Manufacturing Organization. TEM Journal, 8(1), 165-170. 